\title{
Electric field exposure promotes epithelial-mesenchymal transition in human lens epithelial cells via integrin ß1-FAK signaling
}

\author{
JUN LIU ${ }^{1,2}$, XIAO-LONG YAN ${ }^{3}$, XIAO-LIANG ZHENG ${ }^{1}$, LIN MEI $^{1}$, SONG WANG $^{1}$, JING HAN $^{1}$ and HONG YAN ${ }^{1,4}$ \\ ${ }^{1}$ Department of Ophthalmology, Tangdu Hospital, Fourth Military Medical University, Xi'an, Shaanxi 710038; \\ ${ }^{2}$ Department of Ophthalmology, Affiliated Hospital of Shaanxi University of Chinese Medicine, Xian'yang, \\ Shaanxi 712000; ${ }^{3}$ Department of Thoracic Surgery, Tangdu Hospital, Fourth Military Medical University, Xi'an, \\ Shaanxi 710038; ${ }^{4}$ Chongqing Eye Institute, The First Affiliated Hospital of Chongqing Medical University, \\ Chongqing Key Lab of Ophthalmology and Chongqing Eye Institute, Chongqing 400016, P.R. China
}

Received August 21, 2016; Accepted May 17, 2017

DOI: $10.3892 / \mathrm{mmr} .2017 .7086$

\begin{abstract}
Electric field (EF) exposure can affect the elongation, migration, orientation, and division of cells. The present study tested the hypothesis that EF may also affect epithelial-mesenchymal transition (EMT) in lens epithelial cells and that this effect may be an important inducer in the pathological process of posterior capsule opacification (PCO). Human lens epithelial (HLE)-B3 cells were exposed to an EF. Experiments were performed in the presence or absence of an anti-integrin $\beta 1$ blocking antibody or a small molecule inhibitor targeting focal adhesion kinase (FAK). Cell morphology changes were observed by microscopy. The expression levels of integrin $\beta 1$, FAK, phosphorylated (p)FAK and of EMT markers, E-cadherin and Vimentin, were examined by immunofluorescence, reverse transcription-quantitative polymerase chain reaction and western blotting. Following exposure to EF, HLE-B3 cells appeared elongated and resembled more fibroblast-like cells. Expression of E-cadherin was decreased, while expression of Vimentin was increased in HLE-B3 cells exposed to EF, compared with control cells. In addition, the mRNA expression levels of integrin $\beta 1$ were increased, and the protein expression levels of integrin $\beta 1$ and pFAK were increased in HLE-B3 cells exposed to EF, compared with control cells. Blocking of integrin $\beta 1$ suppressed the EMT-related morphological changes of HLE-B3 cells and reduced the activation of FAK following EF exposure. However, blocking of pFAK did not affect the EMT status of HLE-B3 cells induced by EF. In conclusion, the present study demonstrated that EF exposure induced EMT in HLE-B3 cells and that this effect may partially be mediated
\end{abstract}

Correspondence to: Dr Jing Han or Dr Hong Yan, Department of Ophthalmology, Tangdu Hospital, Fourth Military Medical University, 569 Xinsi Road, Xi'an, Shaanxi 710038, P.R. China

E-mail: hanjing.cn@163.com

E-mail: yhongb@fmmu.edu.cn

Key words: posterior capsule opacification, electric field, epithelial-mesenchymal transition, integrin, focal adhesion kinase, human lens epithelial cell by the activation of integrin $\beta 1$-FAK signaling. The present results may provide a new mechanistic approach to prevent the development of PCO.

\section{Introduction}

Posterior capsule opacification (PCO) is the most common postoperative complication following cataract surgery (1) The incidence of adult PCO is $>25 \%$ in the first 5 years postoperatively (2) Pediatric patients are reported to have a higher incidence of PCO, because the lens epithelial cells of children grow faster, therefore they are also more likely to undergo increased migration, proliferation and fibrosis in the posterior capsule(3).PCO is mainly caused by the epithelial-mesenchymal transition (EMT), migration and proliferation of remnant lens epithelial cells (LECs) following cataract surgery $(4,5)$. EMT refers to the process that polarized epithelial cells transform to mesenchymal cells via multiple biochemical changes. The EMT process therefore results in a loss of cell adhesion molecules, such as E-cadherin, and an increase of mesenchymal cell markers, such as Vimentin (6). EMT serves a critical role in embryonic development, fibrosis disease, chronic inflammation, pathological wound healing and cancer progression and metastasis (7). Despite previous studies on the cell proliferation and EMT of LECs, the underlying mechanisms of how LECs change into lens fibers following surgery remain largely unknown. A previous study has demonstrated that the lens has a unique pattern of circulating electric currents, which exit at the lens equator and enter at both poles, serving as an internal circulatory system (8). It is hypothesized that this endogenous electric field (EF) provides a stable internal circulatory system in order to maintain the lens clarity and homeostasis $(8,9)$. Previous findings have suggested that electrical signals lead to distortion, migration, and orientation of LECs, and even regulate LEC division (10-12). However, the cataract surgery removes a large part of the anterior lens capsule and the lens nucleus, which changes the inward electrical currents at the anterior lens surface and significantly disrupts the normal electric current pattern. This abnormal electrical signal may trigger LEC migration and proliferation, and eventually the formation of PCO $(13,14)$. Furthermore, several studies have 
reported that there is a strong association between the integrin signaling pathway, EMT and the development of fibrotic lens disease (15-17).

The present study therefore tested the hypothesis that changes in EF may be an important inducer of EMT in LECs, and that integrin signaling pathways may be involved in the regulation of this process. The results revealed that EF induced EMT in LECs and elicited the activation of integrin-focal adhesion kinase (FAK) signaling. Blocking of integrin $\beta 1$ prevented FAK activation and EMT in LECs following EF exposure, while blocking of FAK had no effect. The results of the present study may provide novel insights for the treatment of patient with $\mathrm{PCO}$.

\section{Materials and methods}

Cell culture. The human lens epithelial (HLE)-B3 cell line was obtained from Zhong Shan Ophthalmic Center of Sun Yat-Sen University (Guangzhou, China). The cells were maintained in Dulbecco's modified Eagle's medium (DMEM; Gibco; Thermo Fisher Scientific, Inc., Waltham, MA, USA) supplemented with $12.5 \%$ fetal bovine serum (Gibco; Thermo Fisher Scientific, Inc.), $100 \mathrm{IU} / \mathrm{ml}$ penicillin and $100 \mu \mathrm{g} / \mathrm{ml}$ streptomycin, at $37^{\circ} \mathrm{C}$ in a $5 \% \mathrm{CO}_{2}$ incubator. The medium was replaced every 2-3 days. Cells were incubated overnight for single-cell experiments, while to form a confluent monolayer, cells were incubated for 2-3 days. For functional blocking of integrin $\beta 1$ subunit, HLE-B3 cell suspensions were incubated with $10 \mu \mathrm{g} / \mathrm{ml}$ of the function blocking antibody MAB1965 (EMD Millipore, Billerica, MA, USA) for $1 \mathrm{~h}$ at $37^{\circ} \mathrm{C}$. In order to block FAK phosphorylation, a novel small molecule inhibitor of FAK was used, PF-573,228 (Tocris Bioscience, Bristol, UK) $(18,19)$. The cells were incubated with $10 \mu \mathrm{M}$ PF-573,228 for $1 \mathrm{~h}$ at $37^{\circ} \mathrm{C}$.

EF application. The cells were exposed to an EF as described by Han et al (20) and Zhao et al (21). Briefly, 2 parallel strips of glass coverslip $2.2 \mathrm{~cm}$-long were fixed $10 \mathrm{~mm}$ apart to the base of a tissue culture dish with silicone grease (DC4; Dow Corning, Midland, MI, USA). Cells were cultured in monolayer in the area between the 2 parallel strips of glass coverslip. A cover glass lid was applied to the shallow culture trough and sealed with silicone grease to create a chamber (22x10x0.3 mm). Agar-salt bridges of $\sim 15 \mathrm{~cm}$ long were used to connect silver/silver chloride electrodes in salt solution to prevent the electrolytic products into the cultures. No significant fluctuation in field strength was observed. The cells were exposed to a $100 \mathrm{mV} / \mathrm{mm} \mathrm{EF}$ for $24 \mathrm{~h}$ at $37^{\circ} \mathrm{C}$ in $5 \% \mathrm{CO}_{2}$ incubator. Control cells were treated identically except for they were not exposed to EF.

Confocal fluorescence microscopy analysis. Following exposure to EF, the cells were washed three times with PBS and fixed with $4 \%$ paraformaldehyde for $20 \mathrm{~min}$ at room temperature. The coverslips were washed three times with PBS and blocked with $10 \%$ normal goat serum (Beyotime Institute of Biotechnology, Haimen, China) in $0.1 \%$ Triton X-100/PBS for $2 \mathrm{~h}$ at $4^{\circ} \mathrm{C}$, then incubated with rabbit anti-human integrin $\beta 1$ antibody (1:300; cat no. SAB4300655; Sigma-Aldrich; Merck KGaA, Darmstadt, Germany), rabbit anti-human Vimentin antibody (1:300; cat no. sc-7557; Santa Cruz Biotechnology,
Inc., Dallas, TX, USA), or rabbit anti-human E-cadherin antibody (1:100; cat no. SAB4503751; Sigma-Aldrich; Merck $\mathrm{KGaA}$ ) for $2 \mathrm{~h}$ at $4^{\circ} \mathrm{C}$. Following washing, the cells were incubated with goat anti-rabbit antibodies conjugated with $\mathrm{Cy} 3$ (1:300; cat no. GB21303; Jingke Huaxue, Shanghai, China) for $1 \mathrm{~h}$ at room temperature and washed three times with PBS. The nuclei were stained with $0.5 \mu \mathrm{g} / \mathrm{ml}$ DAPI (Sigma-Aldrich; Merck $\mathrm{KGaA}$ ) for $10 \mathrm{~min}$ at room temperature. Finally, images were captured with a confocal microscope (FV-1000; Olympus Corporation, Tokyo, Japan).

Reverse transcription-quantitative polymerase chain reaction $(R T-q P C R)$. Total RNA was isolated using TRIzol (Invitrogen; Thermo Fisher Scientific, Inc.), according to the manufacturer's protocol. Total RNA (5 $\mu \mathrm{g})$ was reverse transcribed into cDNA using SuperScript II reverse transcriptase (Invitrogen; Thermo Fisher Scientific, Inc.), according to the manufacturer's protocol. The reaction volume was $20 \mu \mathrm{l}$. RNA and primers were mixed in a $12 \mu \mathrm{l}$ volume and denatured for $5 \mathrm{~min}$ at $65^{\circ} \mathrm{C}$. Then, RT buffer, RNase inhibitor, dNTPs and Revert Aid Reverse Transcriptase were added to a total volume of $20 \mu \mathrm{l}$. The mixture was incubated for $60 \mathrm{~min}$ at $42^{\circ} \mathrm{C}$, followed by $5 \mathrm{~min}$ at $25^{\circ} \mathrm{C}$. The reaction was terminated by incubation at $70^{\circ} \mathrm{C}$ for $5 \mathrm{~min}$. qPCR was performed using SYBR Premix Ex Taq (Takara Biotechnology Co., Ltd., Dalian, China). The reaction mixture contained $2 \mathrm{X}$ SYBR mixture, PCR forward primer, $\mathrm{PCR}$ reverse primer, $\mathrm{cDNA}$ and $\mathrm{dH}_{2} \mathrm{O}$ in a total volume of $20 \mu \mathrm{l}$. Reactions were performed on an Agilent Mx3005P QPCR system (Agilent Technologies, Inc., Santa Clara, CA, USA). Thermocycling conditions were as follows: Initial denaturation at $95^{\circ} \mathrm{C}$ for $10 \mathrm{~min}$, followed by 35 cycles at $95^{\circ} \mathrm{C}$ for $15 \mathrm{sec}$, at $62^{\circ} \mathrm{C}$ for $30 \mathrm{sec}$ and at $72^{\circ} \mathrm{C}$ for $50 \mathrm{sec}$. GAPDH was used as an internal control. Relative gene expression was calculated according to the comparative $\mathrm{Cq}$ method (22) and normalized to GAPDH expression. The sequences of the primers used for qPCR are listed in Table I.

Western blotting. The cells were lysed with radioimmunoprecipitation assay buffer on ice for $1 \mathrm{~h}$ and centrifuged at $14,000 \mathrm{x} \mathrm{g}$ for $30 \mathrm{~min}$ at $4^{\circ} \mathrm{C}$. The supernatant was then harvested and the protein concentration was determined using the bicinchoninic acid protein assay. Equal amounts of extracted protein samples $(50 \mu \mathrm{g})$ were separated by $12 \%$ SDS-PAGE and transferred onto polyvinylidene fluoride membranes. Membranes were blocked with $8 \%$ skimmed milk for $1 \mathrm{~h}$ at room temperature and then were incubated at $4^{\circ} \mathrm{C}$ overnight with antibodies against integrin $\beta 1(1: 1,000$; cat no. SAB4300655; Sigma-Aldrich; Merck KGaA), Vimentin (1:1,000; cat no. sc-7557; Santa Cruz Biotechnology, Inc.), E-cadherin (SAB4503751) (1:1,000; Sigma-Aldrich; Merck KGaA), FAK (1:1,000; cat no. 3285; Cell Signaling Technology, Inc., Danvers, MA, USA), phosphorylated (p)FAK [pY-397] (1:1,000; cat no. D20B1; Cell Signaling Technology, Inc.), and GAPDH (1:1,000; cat no. SAB2100894; Sigma-Aldrich; Merck KGaA). Membranes were then washed with TBS containing $0.1 \%$ Tween-20, and subsequently incubated with secondary horseradish peroxidase (HRP)-conjugated goat anti-rabbit antibodies (1:5,000; cat no. CW0103S; CWBIO, Beijing, China) at $37^{\circ} \mathrm{C}$ for $1 \mathrm{~h}$, followed by color development using the Immobilon Western Chemiluminescent HRP substrate 
Table I. Sequences of primers used for reverse transcription-quantitative polymerase chain reaction.

\begin{tabular}{|c|c|c|c|c|}
\hline Gene & $\begin{array}{c}\text { NCBI } \\
\text { accession no. }\end{array}$ & Primer & Sequence $\left(5^{\prime}-3^{\prime}\right)$ & $\begin{array}{l}\text { Product } \\
\text { size }(b p)\end{array}$ \\
\hline E-cadherin & NM_001317186.1 & $\begin{array}{l}\text { Forward } \\
\text { Reverse }\end{array}$ & $\begin{array}{l}\text { CAAGCAGCAGTACATTCTA } \\
\text { CACTTCCACTCTCTTTTC }\end{array}$ & 148 \\
\hline Vimentin & NM_003380.3 & $\begin{array}{l}\text { Forward } \\
\text { Reverse }\end{array}$ & $\begin{array}{l}\text { AATGGCTCGTCACCTTCG } \\
\text { CTAGTTTCAACCGTCTTAATCAG }\end{array}$ & 225 \\
\hline Integrin $\beta 1$ & NM_002211.3 & $\begin{array}{l}\text { Forward } \\
\text { Reverse }\end{array}$ & $\begin{array}{l}\text { GCCTTACATTAGCACAACACC } \\
\text { CATCTCCAGCAAAGTGAAACC }\end{array}$ & 284 \\
\hline GAPDH & NM_001289746.1 & $\begin{array}{l}\text { Forward } \\
\text { Reverse }\end{array}$ & $\begin{array}{l}\text { GTCGGAGTCAACGGATTT } \\
\text { ACTCCACGACGTACTCAG }\end{array}$ & 277 \\
\hline
\end{tabular}

A

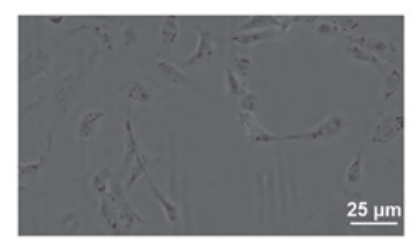

B

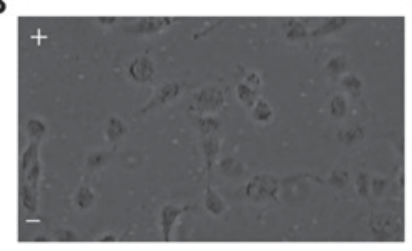

$6 \mathrm{~h}$
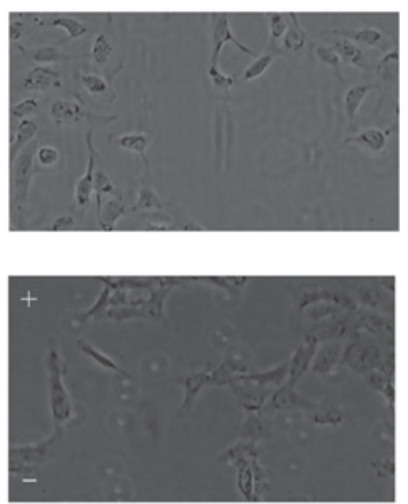

$12 \mathrm{~h}$
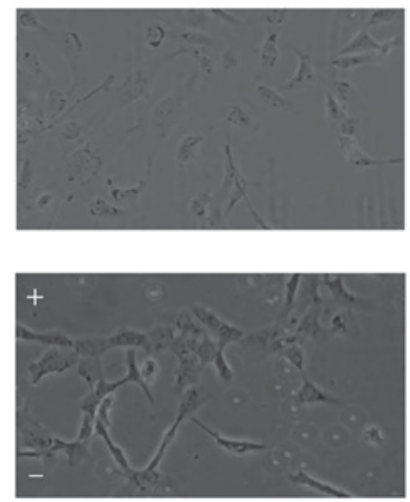

$24 \mathrm{~h}$
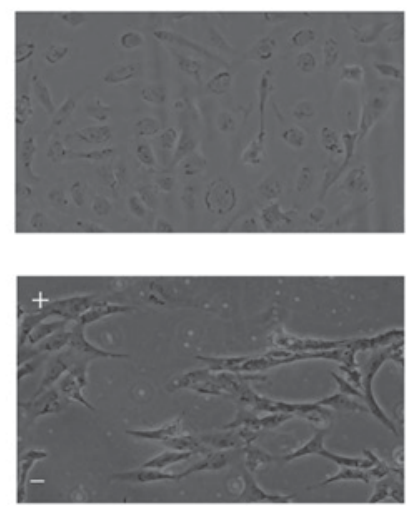

Figure 1. EF exposure induces morphological changes in HLE-B3 cells. (A) HLE-B3 cells exhibited a cobblestone-like morphology in the absence of EF. (B) The cells were exposed to an EF of $100 \mathrm{mv} / \mathrm{mm}$ for 6, 12 and $24 \mathrm{~h}$. Following EF exposure, the cells appeared larger and elongated, with a fibroblast-like or long spindle-shaped morphology, compared with untreated cells. Scale bar, $25 \mu \mathrm{m}$. EF, electric field; -, cathode; +, anode.

(EMD Millipore) and observation under a chemiluminescence analyzer (Bio-Rad Laboratories, Inc., Hercules, CA, USA). Blots were semi-quantified by densitometry using Adobe Photoshop software version 2015 (Adobe Systems, Inc., San Jose, CA, USA).

Statistical analysis. All experiments were repeated at least three times independently. Data are expressed as the mean \pm standard deviation. Statistical analysis was performed with GraphPad Prism software version 5.0 (GraphPad Software, Inc., La Jolla, CA, USA). The statistical significance of the differences between groups was assessed using one-way analysis of variance followed by Tukey's post hoc test. $\mathrm{P}<0.05$ was considered to indicate a statistically significant difference.

\section{Results}

EF induces morphologic changes in HLE-B3 cells. Untreated HLE-B3 cells exhibited an appearance of polygon monolayer or cuboidal shape when examined by microscopy analysis (Fig. 1A). However, the cells lost their epithelial cell morphology and acquired a mesenchymal appearance starting at $6 \mathrm{~h}$ of EF exposure (Fig. 1B). The EF-exposed cells appeared elongated and exhibited a fibroblast-like appearance with a long spindle-shape and larger intercellular spaces (Fig. 1B).

Effect of EF on expression of E-cadherin and Vimentin in HLE-B3 cells. EMT is characterized by loss of epithelial makers, such as E-cadherin, and replacement by mesenchymal markers, such as Vimentin (23). HLE-B3 cells were exposed to an EF of $100 \mathrm{mV} / \mathrm{mm}$ for $24 \mathrm{~h}$, and then the levels of E-cadherin and Vimentin were examined by immunofluorescence. The results revealed that EF exposure decreased the expression of the epithelial marker E-cadherin, while it increased the expression of the mesenchymal marker Vimentin (Fig. 2A). The mRNA expression levels of E-cadherin and Vimentin were also examined by RT-qPCR, and the results confirmed a significant shift of gene expression from a pattern characteristic of epithelial cells to that of mesenchymal cells in HLE-B3 cells following $24 \mathrm{~h}$ of EF exposure. The mRNA expression levels of E-cadherin decreased to $35 \%(\mathrm{P}<0.01)$ and the mRNA expression of Vimentin increased by $90 \%(\mathrm{P}<0.01)$ compared with control (Fig. 2B). At the protein expression level, E-cadherin protein levels decreased by $\sim 70 \%(\mathrm{P}<0.01)$ and Vimentin protein levels increased by approximately 400\% (P<0.01) compared with control (Fig. 2C). 

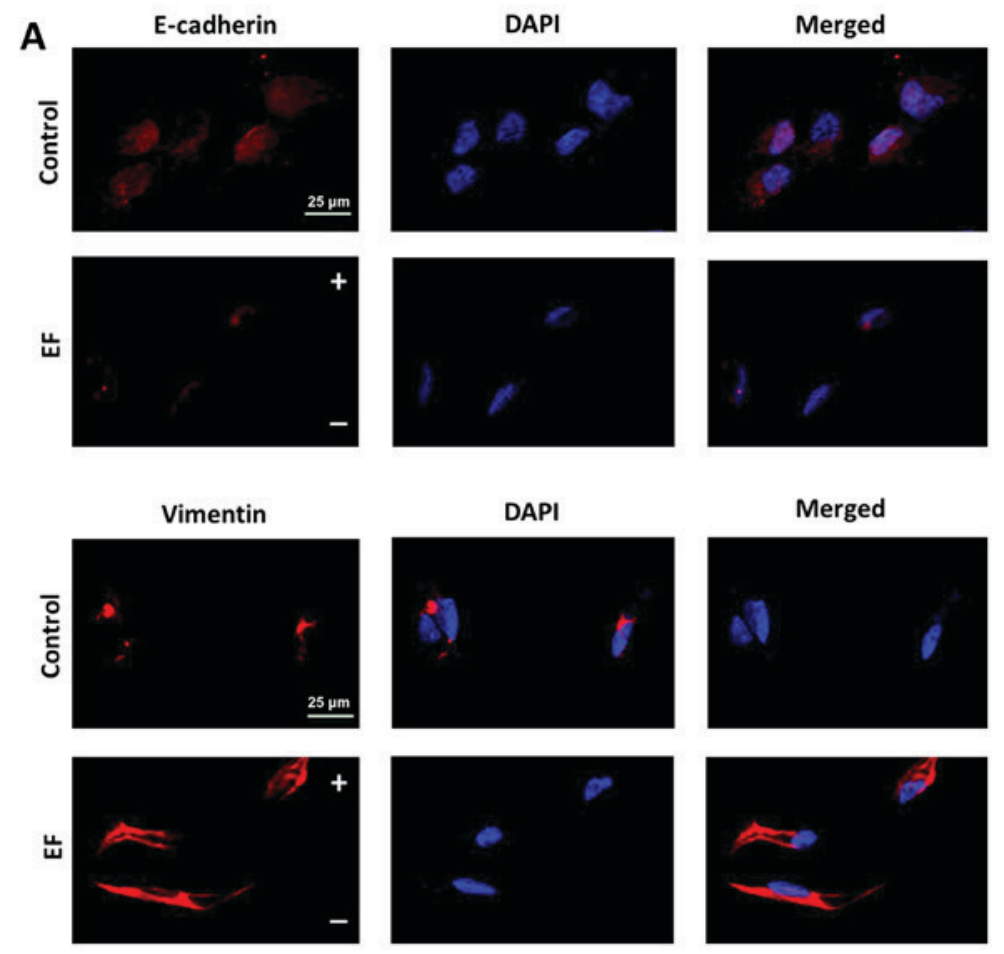

B
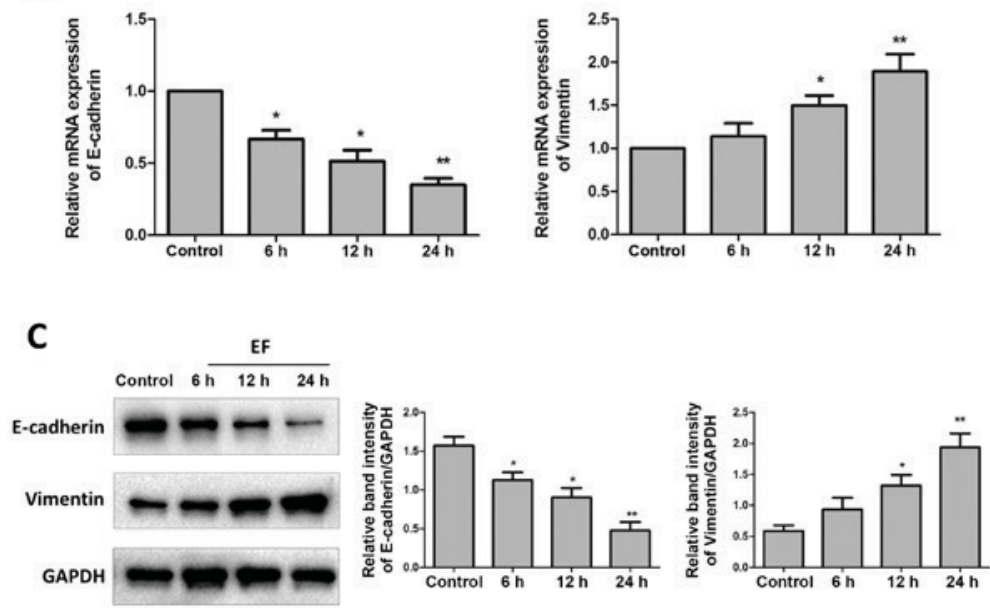

Figure 2. EF exposure promotes expression of EMT markers in HLE-B3 cells. Cells were examined for expression of E-cadherin and Vimentin, without (control) or with (EF) exposure to an EF of $100 \mathrm{mV} / \mathrm{mm}$. (A) Immunofluorescent staining of EMT markers (red) following $24 \mathrm{~h}$ EF exposure. Nuclei were counterstained with DAPI (blue). Scale bar, $25 \mu \mathrm{m}$. (B) Reverse transcription-quantitative polymerase chain reaction analysis following 6 , 12 , and $24 \mathrm{~h}$ EF exposure. (C) Western blot analysis following 6, 12, and $24 \mathrm{~h} \mathrm{EF}$ exposure. Data were presented as mean + standard deviation. ${ }^{*} \mathrm{P}<0.05$ and ${ }^{* *} \mathrm{P}<0.01 \mathrm{vs}$. control. EF, electric field; EMT, epithelial-mesenchymal transition; -, cathode; +, anode.

EF exposure promotes integrin $\beta 1$ expression and FAK activation in HLE-B3 cells. Results from immunofluorescence analysis revealed that EF exposure increased the expression of integrin $\beta 1$ in HLE-B3 cells compared with control cells (Fig. 3A). RT-qPCR analysis confirmed that exposure to EF for $24 \mathrm{~h}$ stimulated an increase in the mRNA expression of integrin $\beta 1$ in HLE-B3 cells by 3.35-fold, compared with control cells $(\mathrm{P}<0.01$; Fig. 3B). Finally, the protein expression levels of integrin $\beta 1$ were examined as well, and an increase of $\sim 4.43$-fold was observed following EF exposure for $24 \mathrm{~h}$ compared with control cells $(\mathrm{P}<0.01$; Fig. $3 \mathrm{C})$. Because activation of FAK is one of the key events in the integrin signaling cascade, phosphorylation of FAK in the HLE-B3 cells following exposure to EF was examined by western blot analysis. Exposure to EF for 6, 12 and $24 \mathrm{~h}$, while not affecting the levels of total FAK protein, resulted in a significant increase in the levels of pFAK by 2.09 -fold $(\mathrm{P}<0.05), 2.84$-fold $(\mathrm{P}<0.01)$ and 4.07 -fold $(\mathrm{P}<0.01)$, respectively, compared with control cells (Fig. 3C).

Inhibition of integrin $\beta 1$ affects abolishes the EF-induced $E M T$. To further explore the role of integrin $\beta 1$ and FAK in the EF-induced EMT in HLE-B3 cells, the integrin $\beta 1$ specific blocking antibody MAB1965, and the small molecule inhibitor of pFAK PF-573,228, were used in the present study. When HLE-B3 cells were pretreated with MAB1965, EF exposure failed to affect their cell morphology, and the cells retained 
A

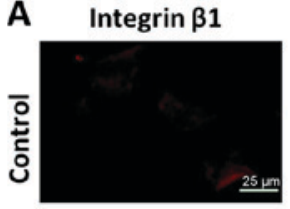

出

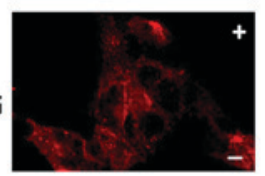

DAPI
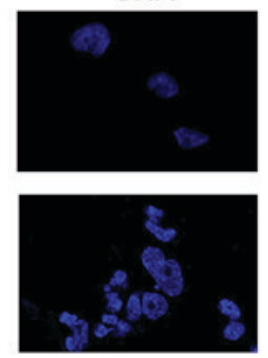

Merged
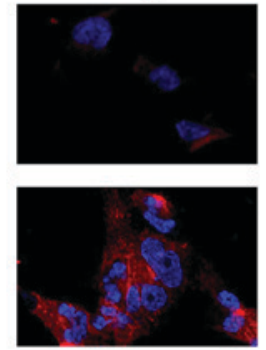

B

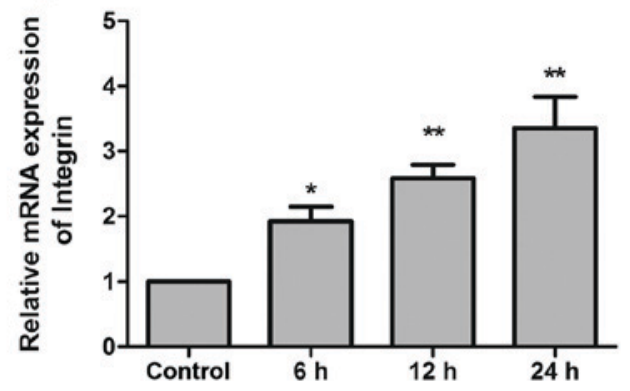

C
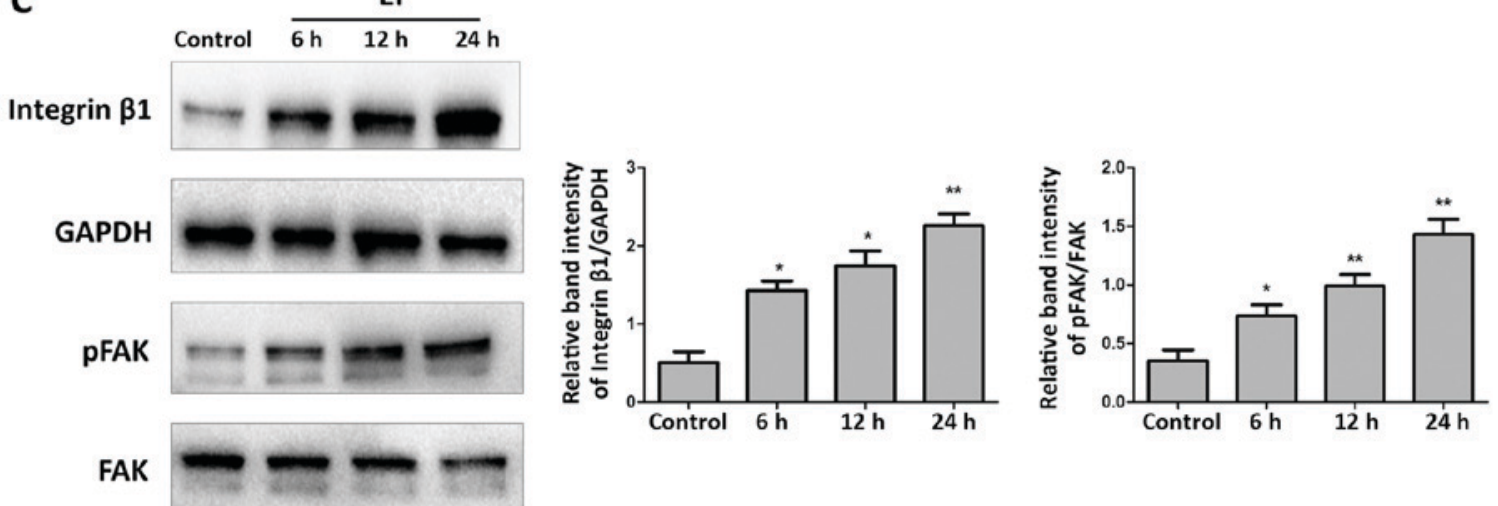

Figure 3. EF exposure activates integrin $\beta 1 / F A K$ signaling. (A) Immunofluorescent staining for integrin $\beta 1$ (red) in control group and EF-treated group for $24 \mathrm{~h}$. Nuclei were counterstained with DAPI (blue). Scale bar, $25 \mu \mathrm{m}$. (B) Reverse transcription-quantitative polymerase chain reaction analysis of integrin $\beta 1 \mathrm{mRNA}$ expression levels following 6, 12, and $24 \mathrm{~h}$ EF exposure. (C) Western blot analysis for the protein expression levels of integrin $\beta 1$, pFAK and total FAK following 6, 12, and $24 \mathrm{~h}$ EF exposure. Data were presented as mean + standard deviation. ${ }^{*} \mathrm{P}<0.05$ and ${ }^{* *} \mathrm{P}<0.01 \mathrm{vs}$. control. EF, electric field; FAK, focal adhesion kinase; p, phosphorylated; -, cathode; +, anode.

A
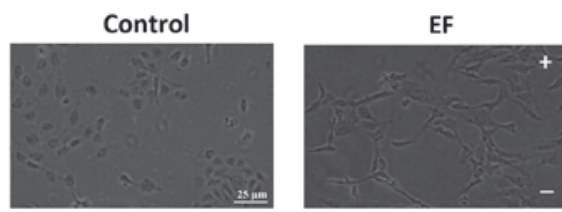

B

Vimentin

GAPDH

PFAK

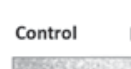

EF

$E F+$
MAB1965

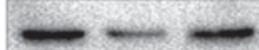

-

FAK
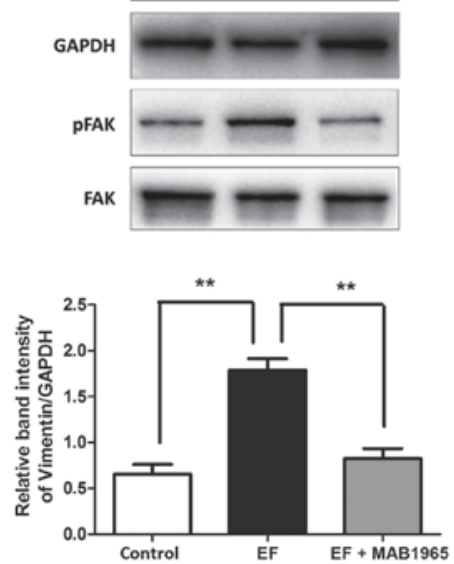
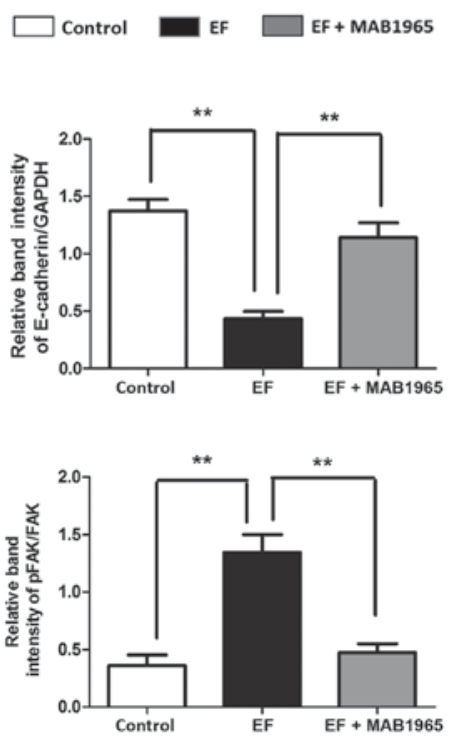

Figure 4. Effect of integrin $\beta 1$ inhibition on EF-induced EMT. (A) Cell morphology was observed by microscopy in HLE-B3 cells following EF exposure, with or without pretreatment with the integrin $\beta 1$ function blocking antibody MAB1965. Scale bar, $25 \mu \mathrm{m}$. (B) Western blot analysis of HLE-B3 cells following EF exposure, with or without pretreatment with MAB1965. Data were presented as mean + standard deviation. ${ }^{* *} \mathrm{P}<0.01$, with comparisons indicated by lines. EF, electric field; EMT, epithelial-mesenchymal transition; p, phosphorylated; FAK, focal adhesion kinase; -, cathode; +, anode. 
A
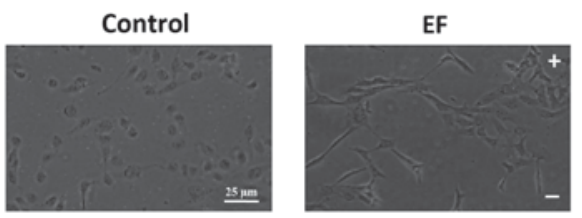

EF + PF573,288

B
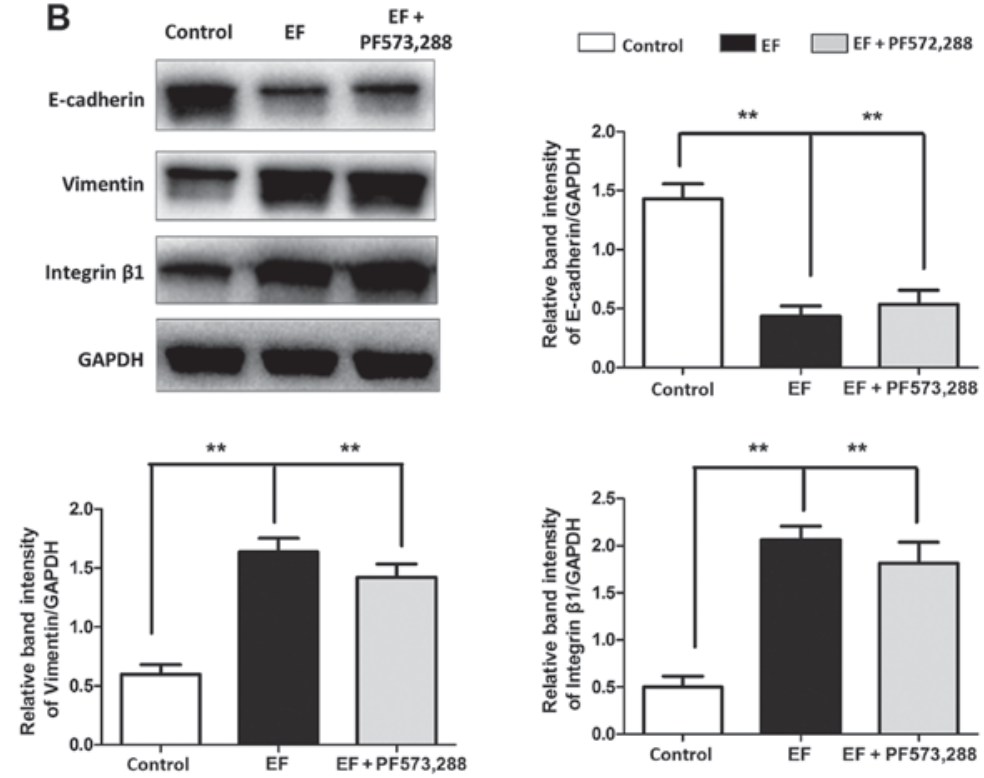

Figure 5. Effect of FAK inhibition on EF-induced EMT. (A) Cell morphology was observed by microscopy in HLE-B3 cells following EF exposure, with or without pretreatment with the pFAK specific inhibitor PF-573,288. Scale bar, $25 \mu \mathrm{m}$. (B) Western blot analysis of HLE-B3 cells following EF exposure, with or without pretreatment with PF-573,288. Data were presented as mean + standard deviation. ${ }^{* *} \mathrm{P}<0.01$, with comparisons indicated by lines. FAK, focal adhesion kinase; EF, electric field; EMT, epithelial-mesenchymal transition; p, phosphorylated; -, cathode; +, anode.

their epithelial-like cuboidal shape (Fig. 4A). Notably, the EF-induced changes in the protein expression levels of E-cadherin, Vimentin and the ratio of pFAK/FAK were almost completely reversed by MAB1965 pretreatment to the levels of the control untreated cells (Fig. 4B). By contrast, PF-573,288 pretreatment did not attenuate the EF-induced effects. Cells pretreated with PF-573,288 exhibited a fibroblast-like morphology following EF exposure, similar to the EF-exposed cells alone (Fig. 5A). Furthermore, the protein expression levels of E-cadherin, Vimentin and integrin $\beta 1$ were not affected by PF-573,288 pretreatment compared with the EF-exposed cells alone (Fig. 5B).

\section{Discussion}

Previous studies have reported that EFs have various effects on ocular cell behavior, including cell migration, division and proliferation $(8,11,24,25)$. Wang et al (12) observed that LECs expanded and flattened in an applied EF. They proposed that EF may sequester growth factors, such as the fibroblast growth factor, and thus create gradients involved in EMT (12). In the present study, HLE-B3 cells were demonstrated to exhibit an elongated and fibroblast-like cell morphology following exposure to EF, confirming that EF can induce morphological changes in LECs under certain conditions. The results also demonstrated that expression of the epithelial marker E-cadherin was downregulated, while expression of the mesenchymal marker Vimentin was upregulated in HLE-B3 cells following EF exposure, suggesting that EF may induce EMT in LECs.

Previous studies have suggested that integrin $\beta 1$ signaling may serve an important role in EMT. The engagement of integrin $\beta 1$ with collagen type I results in loss of E-cadherin and indirect upregulation of $\mathrm{N}$-cadherin, which directly leads to EMT $(26,27)$. It has been reported that expression of integrin $\beta 1$ is increased in the kidneys of patients with chronic tubulointerstitial fibrosis, and that blockage of integrin $\beta 1$ signaling in an animal model of unilateral ureteral obstruction alleviates renal fibrosis (28). A previous study from our group has demonstrated that EF-induced migration in retinal pigment epithelial cells may involve the upregulation of integrin $\beta 1$ subunit and the activation of FAK (29). The present study demonstrated that the expression of integrin $\beta 1$ was upregulated by EF exposure, and that the blockage of integrin $\beta 1$ significantly inhibited the expression of EMT markers in HLE-B3 cells. Taken together, the present results suggest that integrin signaling might be a critical mediator in the EMT transformation induced by EF.

Integrins are a large family of transmembrane, adhesion molecules on the cell surface. Their binding to components of the extracellular matrix and subsequent activation requires the action of kinases to enable signal transduction. FAK is a non-receptor tyrosine kinase, whose phosphorylation and tyrosine protein kinase activity is triggered by integrin clustering and ligation to initiate signal transduction $(30,31)$. In the present study, blocking of integrin $\beta 1$ reduced the activation 
of FAK and inhibited EMT in HLE-B3 cells following EF exposure. These results further demonstrated a functional relationship between integrin $\beta 1$ and FAK in response to $\mathrm{EF}$ exposure. However, blockage of FAK with the PF-573,288 specific inhibitor did not attenuate the EF-induced EMT in HLE-B3 cells, suggesting that downstream regulators other than FAK may be involved in the role of integrin $\beta 1$ in the EF-induced EMT. It is known that EMT is regulated by a variety of signals. For example, it has been reported that integrin $\beta 1$ induces EMT through activating transforming growth factor- $\beta(32,33)$. Therefore, the present results indicated that the EF-induced EMT in LECs may be mediated through, but not limited, the integrin $\beta 1$-FAK signaling pathway.

In conclusion, EF exposure induced EMT in HLE-B3 cells, which may partially be mediated through activation of integrin $\beta 1-F A K$ signaling. EFs may therefore be crucial regulators of LEC behavior via inducing EMT following cataract surgery. Clinically, inhibition of this effect may provide new insights into the treatment of PCO.

\section{Acknowledgements}

This work was supported by the National Natural Science Foundation of China (grant no. 81200671).

\section{References}

1. Apple DJ, Solomon KD, Tetz MR, Assia EI, Holland EY, Legler UF, Tsai JC, Castaneda VE, Hoggatt JP and Kostick AM: Posterior capsule opacification. Surv Ophthalmol 37: 73-116, 1992

2. Lundqvist B and Mönestam E: Ten-year longitudinal visual function and Nd: YAG laser capsulotomy rates in patients less than 65 years at cataract surgery. Am J Ophthalmol 149: 238-244, 2010.

3. Knight-Nanan D, O'Keefe $\mathrm{M}$ and Bowell R: Outcome and complications of intraocular lenses in children with cataract. J Cataract Refract Surg 22: 730-736, 1996.

4. Marcantonio JM and Vrensen GF: Cell biology of posterior capsular opacification. Eye(Lond) 13: 484-488, 1999.

5. Yang Y, Ye Y, Lin X, Wu K and Yu M: Inhibition of pirfenidone on TGF-beta2 induced proliferation, migration and epithlial-mesenchymal transition of human lens epithelial cells line SRA01/04. PloS One 8: e56837, 2013.

6. Savagner P: The epithelial-mesenchymal transition (EMT) phenomenon. Ann oncol 21 (Suppl 7): S89-S92, 2010

7. Kalluri R and Weinberg RA: The basics of epithelial-mesenchymal transition. J Clin Invest 119: 1420-1428, 2009.

8. Zhao M, Chalmers L, Cao L, Vieira AC, Mannis M and Reid B: Electrical signaling in control of ocular cell behaviors. Prog Retin Eye Res 31: 65-88, 2012.

9. Mathias RT, Rae JL and Baldo GJ: Physiological properties of the normal lens. Physiol Rev 77: 21-50, 1997.

10. Wang E, Zhao M, Forrester JV and McCaig CD: Electric fields and MAP kinase signaling can regulate early wound healing in lens epithelium. Invest Ophthalmol Vis Sci 44: 244-249, 2003.

11. Wang E, Zhao M, Forrester JV and McCaig CD: Bi-directional migration of lens epithelial cells in a physiological electrical field. Exp Eye Res 76: 29-37, 2003.

12. Wang E, Zhao M, Forrester JV and MCCaig CD: Re-orientation and faster, directed migration of lens epithelial cells in a physiological electric field. Exp Eye Res 71: 91-98, 2000.

13. Wang E, Reid B, Lois N, Forrester JV, McCaig CD and Zhao M: Electrical inhibition of lens epithelial cell proliferation: An additional factor in secondary cataract? Faseb J 19: 842-844, 2005.
14. Lois N, Reid B, Song B, Zhao M, Forrester J and McCaig C: Electric currents and lens regeneration in the rat. Exp Eye Res 90: 316-323, 2010.

15. Gil D, Ciołczyk-Wierzbicka D, Dulińska-Litewka J, Zwawa K, McCubrey JA and Laidler P: The mechanism of contribution of integrin linked kinase (ILK) to epithelial-mesenchymal transition (EMT). Adv Enzyme Regul 51: 195-207, 2011.

16. Walker $\mathrm{J}$ and Menko AS: Integrins in lens development and disease. Exp Eye Res 88: 216-225, 2009.

17. Borok Z: Role for alpha3 integrin in EMT and pulmonary fibrosis. J Clin Invest 119: 7-10, 2009.

18. Xu B, Song G and Ju Y: Effect of focal adhesion kinase on the regulation of realignment and tenogenic differentiation of human mesenchymal stem cells by mechanical stretch. Connect Tissue Res 52: 373-379, 2011.

19. Slack-Davis JK, Martin KH, Tilghman RW, Iwanicki M, Ung EJ, Autry C, Luzzio MJ, Cooper B, Kath JC, Roberts WG and Parsons JT: Cellular characterization of a novel focal adhesion kinase inhibitor. J Biol Chem 282: 14845-14852, 2007.

20. Han J, Yan XL, Han QH, Li Y, Zhu J and Hui YN: Electric fields contribute to directed migration of human retinal pigment epithelial cells via interaction between F-actin and betal integrin. Curr Eye Res 34: 438-446, 2009.

21. Zhao M, Agius-Fernandez A, Forrester JV and McCaig CD: Orientation and directed migration of cultured corneal epithelial cells in small electric fields are serum dependent. J Cell Sci 109: 1405-1414, 1996.

22. Livak KJ and Schmittgen TD: Analysis of relative gene expression data using real-time quantitative PCR and the 2(-Delta Delta C(T)) Method. Methods 25: 402-408, 2001.

23. Kalluri R and Neilson EG: Epithelial-mesenchymal transition and its implications for fibrosis. J Clin Invest 112: 1776-1784, 2003.

24. Gamboa OL, Pu J, Townend J, Forrester JV, Zhao M, McCaig C and Lois N: Electrical estimulation of retinal pigment epithelial cells. Exp Eye Res 91: 195-204, 2010.

25. Zhao M, McCaig CD, Agius-Fernandez A, Forrester JV and Araki-Sasaki K: Human corneal epithelial cells reorient and migrate cathodally in a small applied electric field. Curr Eye Res 16: 973-984, 1997.

26. Shintani Y,Fukumoto Y, Chaika N, Svoboda R, Wheelock MJ and Johnson KR: Collagen I-mediated up-regulation of N-cadherin requires cooperative signals from integrins and discoidin domain receptor 1. J Cell Biol 180: 1277-1289, 2008.

27. Koenig A, Mueller C, Hasel C, Adler G and Menke A: Collagen type I induces disruption of E-cadherin-mediated cell-cell contacts and promotes proliferation of pancreatic carcinoma cells. Cancer Res 66: 4662-4671, 2006.

28. Yeh YC, Wei WC, Wang YK, Lin SC, Sung JM and Tang MJ: Transforming growth factor- $\{$ beta 1 induces Smad3-dependent \{beta\}1 integrin gene expression in epithelial-to-mesenchymal transition during chronic tubulointerstitial fibrosis. Am J Pathol 177: 1743-1754, 2010.

29. Han J, Yan XL, Han QH, Li YJ, Du ZJ and Hui YN: Integrin $\beta 1$ subunit signaling is involved in the directed migration of human retinal pigment epithelial cells following electric field stimulation. Ophthalmic Res 45: 15-22, 2011.

30. Santos AR, Corredor RG, Obeso BA, Trakhtenberg EF, Wang Y, Ponmattam J, Dvoriantchikova G, Ivanov D, Shestopalov VI, Goldberg JL, et al: $\beta 1$ integrin-focal adhesion kinase (FAK) signaling modulates retinal ganglion cell (RGC) survival. PloS One 7: e48332, 2012

31. Yao K, Tan J, Ye P, Wang K, Xu W, ShenTu X and Tang X: Integrin beta1-mediated signaling is involved in transforming growth factor-beta2-promoted migration in human lens epithelial cells. Mol Vis 13: 1769-1776, 2007.

32. Mamuya FA and Duncan MK: $\mathrm{aV}$ integrins and TGF- $\beta$-induced EMT: A circle of regulation. J Cell Mol Med 16: 445-455, 2012.

33. Parvani JG, Galliher-Beckley AJ, Schiemann BJ and Schiemann WP: Targeted inactivation of $\beta 1$ integrin induces $\beta 3$ integrin switching, which drives breast cancer metastasis by TGF- $\beta$. Mol Biol Cell 24: 3449-3459, 2013. 